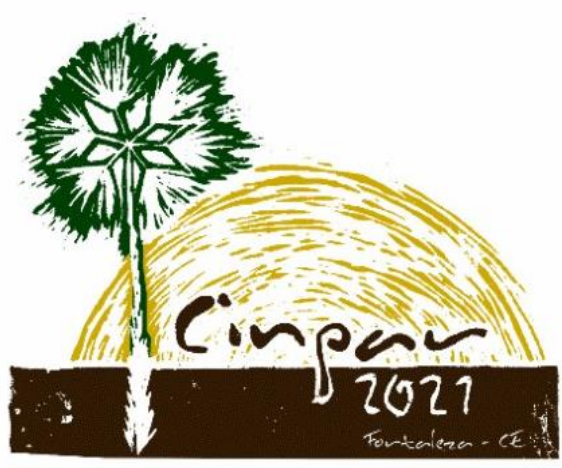

XVII Congresso Internacional sobre Patologia e

Reabilitação das Construções

XVII Congreso Internacional sobre Patología y Rehabilitación de las Construcciones

XVII International Conference on Pathology and Constructions Rehabilitation

FORTALEZA (Brasil), 3 a 5 de junho de 2021

https://doi.org/10.4322/CINPAR.2021.141

\title{
Análise de Manifestações Patológicas em Imóveis Urbanos nas Margens de Rodovias
}

\section{Analysis Of Building Pathologies In Urban Properties On The Border Of The Roads}

\author{
Gregório BECK DA SILVA GIANNAKOS ${ }^{1}$, Mauricio MANCIO ${ }^{2}$ \\ ${ }^{1}$ Universidade do Vale do Rio dos Sinos, São Leopoldo, Brasil, gregorio_giannakos@hotmail.com \\ 2 Universidade do Vale do Rio dos Sinos, São Leopoldo, Brasil, mancio@unisinos.br
}

\begin{abstract}
Resumo: As manifestações patológicas podem ter origem de diferentes etapas do ciclo de vida de uma edificação: projeto, implantação e uso. A inspeção predial é etapa importante para identificar estas anomalias, fazer um diagnóstico preciso e antecipar as terapias que poderiam ser necessárias. O presente estudo tem como objetivo identificar as manifestações patológicas identificadas em 155 imóveis vistoriados em duas cidades brasileiras, com diferentes finalidades (comercial ou residencial) e tipologias (casa, prédio, loja, pavilhão), e correlacionar com o respectivo fenômeno causador do defeito. Ainda, o trabalho correlaciona a localização do imóvel, sua finalidade de uso, frequência de manutenção da edificação e idade da construção com as manifestações patológicas encontradas. Em países ainda em desenvolvimento, como Brasil, a manutenção dos imóveis muitas vezes não é feita ou é realizada de forma inadequada, principalmente quando estes são afastados dos principais centros urbanos, o que torna a inspeção predial uma atividade rara, entretanto de suma importância.
\end{abstract}

Abstract: Pathological manifestations can originate from different stages in the life cycle of a building: design, implantation and use. Building inspection is an important step to identify these anomalies, make an accurate diagnosis and anticipate the therapies that could be necessary. The present study aims to identify the pathological manifestations identified in 155 properties surveyed in two Brazilian cities, with different purposes (commercial or residential) and typologies (house, building, store, pavilion), and correlate with the respective phenomenon causing the defect. Still, the work correlates the location of the property, its purpose of use, frequency of maintenance of the building and age of the construction with the pathological manifestations found. In developing countries, such as Brazil, the maintenance of properties is often not done or is performed inappropriately, especially when they are removed from the main urban centers, which makes building inspection a rare activity, however of paramount importance.

Palavras-chave: Patologia das edificações. Manutenção. Inspeção predial. Buiding pathology. Maintenance. Building Inspection.

\section{Introdução}

Segundo dados constantes no site do IBGE, temos que a população brasileira estimada para 2019 é de 210 milhões de pessoas, enquanto que em nos anos 2000 eram 170 milhões de habitantes, aumento de 23,52\%. Quanto a frota de veículos, segundo o IBGE (2020) no ano de 2006 tinham 27.700 .000 mil automóveis e 1.700.000 caminhões, enquanto que em 2018 tinham 54.700 .000 mil automóveis e 2.800 .000 caminhões, aumentos de $97,47 \%$ e $64,70 \%$, respectivamente. 
Com o aumento da população e frota de veículos, a indústria da construção civil está tendo que atender uma demanda não apenas de imóveis residenciais e comerciais, mas também a demanda de desenvolvimento da infraestrutura (rodovias, viadutos, entre outros).

Segundo Mehta e Monteiro (2008) existem seis razões para o concreto ser tão utilizado na engenharia civil: i) resistência a água/umidade superior ao da madeira e do aço comum, possibilitando seu uso em ambientes industriais e natural ; ii) variabilidade de formas e tamanhos que podem ser alcançados através da plasticidade do concreto fresco; iii) baixo custo e disponibilidade do material; iv) concreto não corrói, não necessitando de tratamento superficial, tendo sua resistência aumentada com o tempo; v) resistência ao fogo; vi) resistência ao carregamento cíclico.

As manifestações patológicas são decorrentes de negligencia por parte dos responsáveis por determinadas ações, da desconsideração de agentes agressivos ou pouco conhecimento do processo degenerativo. $\mathrm{O}$ autor ainda aponta que a maioria das manifestações patológicas são causadas por omissões, detalhamentos de projetos mal feitos ou falta de estudo das interferências dos projetos (THOMAZ, 2001a).

Segundo Cánovas (1988) a inspeção da estrutura danificada ocorre através de exame visual para estimar os danos e suas consequências. Recomenda, ainda, o levantamento de informações relativas às condições do prédio e seu histórico de reparos, comprovação em plantas e levantamento dos danos, localização de erros de projeto, falhas de execução e deficiente conservação e uso da estrutura.

Com o desenvolvimento dos materiais e técnicas construtivas no setor da construção civil, as normas já existentes tiveram de ser atualizadas e novas normas foram criadas. Tornou-se necessário a consideração de fatores que garantam maior durabilidade e desempenho das estruturas e seus sistemas, prolongando a vida útil dos componentes.

Desta forma, o presente artigo tem como objetivo geral fazer levantamento das manifestações patológicas constatadas nas 155 benfeitorias vistoriadas. Como objetivos específicos, busca-se correlacionar o contexto da localização com as manifestações patológicas identificadas, quantificar a diferença de frequência de manutenção entre regiões residenciais e comerciais e identificar a etapa do ciclo de vida das edificações que origina o maior número de manifestações patológicas.

\section{Inspeção e Manifestações Patológicas}

Vistorias, inspeções, auditorias, perícias e consultorias são os procedimentos técnicos investigativos que servem de ferramenta para a Engenharia Diagnóstica, com propósitos específicos e delimitados (GOMIDE; NETO; GULLO, 2009).

Neste mesmo sentido, o termo de "vistoria" é normatizado nas NBRs 14.653-1 e 13.752. De acordo com a NBR 14.653-1, item 3.1.60, vistoria é "Constatação local, presencial, de fatos e aspectos mediante observações criteriosas em um bem e nos elementos e condições que o constituem ou influenciam". Enquanto que na NBR 13.752, item 3.77, "Constatação de um fato, mediante exame circunstanciado e descrição minuciosa dos elementos que o constituem.".

Neste mesmo sentido, a NBR 16.747 caracteriza inspeção predial como um processo que tem como ajudar na gestão da edificação, mitigando riscos técnicos e econômicos associados a perda de desempenho da estrutura e seus sistemas. Dentre as etapas constantes desta norma constam vistoria da edificação e seus sistemas, classificação das irregularidades constatadas e recomendações para restaurar ou preservar o desempenho dos sistemas e elementos afetados por falhas de uso, falta de manutenção ou manifestações patológicas constatadas.

A NBR 16.747 classifica vistoria como o processo de constatação no local, geralmente visual, do desempenho em uso da edificação e seus sistemas.

\subsection{Manifestações Patológicas}

O presente subcapítulo será dividido em três subitens, o primeiro referente a movimentação das fundações. Em seguida, o segundo apresenta os problemas por ocorrência de umidade nas edificações. Enquanto que o terceiro subcapítulo descreve corrosão em armaduras de elementos de concreto armado. 


\subsubsection{Movimentação das Fundações}

O aparecimento de fissuras nos elementos estruturais é a manifestação reconhecível decorrente da movimentação das fundações. Sempre que as tensões geradas nos componentes da edificação ou conexão entre elementos, seja por recalque de fundações de pilares internos, de canto, superarem a resistência dos componentes, aparecerão fissuras (MILITITSKY; CONSOLI; SCHNAID, 2015).

Dentre os diversos motivos para ocorrerem recalques acentuados, destacam-se: recalques em fundações diretas apoiadas sobre aterros mal compactados, ou seção mista de corte e aterro; desconfinamento dos solos, recorrente em centros urbanos, com escavações de subsolos nas vizinhanças; acesso de água às fundações, aumentando a deformabilidade dos solos; falta de compactação ou proteção adequada de taludes (THOMAZ, 2001b).

\subsubsection{Umidade nas edificações}

Segundo Verçoza (1989), a manifestação patológica por infiltração de umidade é uma das mais frequentes nas construções. Seus principais sintomas são penetração de água ou formação de manchas escurecidas e são encontradas principalmente em telhados, lajes de cobertura, paredes e pisos.

Os problemas de umidade podem ser classificados conforme sua origem e manifestação patológica. Assim, classifica-se: umidade de obra, umidade de absorção e capilaridade, umidade de infiltração, umidade de condensação e umidade acidental (PEREZ, 1988).

Segundo estudo feito por Richter (2007), que aborda a qualidade de empreendimentos de habitações de baixa renda, executados em alvenaria estrutural, diagnostica diversas manifestações patológicas em unidades habitacionais. Dentre as manifestações identificadas como mais frequentes, foi constatado umidade por infiltração nas faces internas das paredes externas. Comprovando que, mesmo com o desenvolvimento da tecnologia dos materiais e evolução das técnicas de projeto e execução na construção civil, as edificações seguem apresentando sintomas patológicos.

\subsubsection{Corrosão de Armadura}

Conforme Helene (1988), pode-se definir corrosão como a interação destrutiva de um material com o meio ambiente através de reações químicas ou eletroquímicas.

A solução nos poros do concreto armado e entorno das barras de aço são altamente alcalinas, com pH entre 13 e 14, o que possibilita a existência de um filme de passivação na superfície da armadura, protegendo-a da corrosão. Entretanto, quando há penetração na estrutura por cloretos ou gás carbônico (CO2), ocorre gradual neutralização do $\mathrm{pH}$ da solução dos poros do concreto, que causam a despassivação da armadura e iniciam o processo de corrosão (TUUTTI, 1982).

Os danos estruturais ligados à corrosão da armadura dos elementos de concreto armado são: perda de aderência entre aço e concreto e diminuição da seção transversal da barra de aço, o que compromete sua capacidade de carga (MEHTA; MONTEIRO, 2008).

\section{Método de Trabalho}

Para aplicação da pesquisa em questão, realizou-se estudo de trabalhos técnicos de engenharia para identificar e quantificar as manifestações patológicas nas edificações vistoriadas. As vistorias foram realizadas com o propósito de identificar e relatar as manifestações patológicas existentes em cada imóvel para fins de realizar registro prévio para possíveis intercorrências no decorrer das obras, conforme Imagem 01.

Foram vistoriadas 189 unidades autônomas, com o objetivo de identificar as manifestações patológicas existentes em cada edificação. $O$ trabalho de campo foi dividido em vistorias detalhadas e simplificadas, imóveis comerciais e residenciais. As vistorias simplificadas se caracterizam imóveis nos quais não foi possível acessar, seja por não encontrar o proprietário ou por não autorizarem o trabalho, e por isso não serão consideradas na presente pesquisa. 
No decorrer da elaboração do laudo, através das observações feitas em campo, foram identificadas as possíveis origens das manifestações patológicas. Assim, foram contabilizados a quantidade de imóveis em que estas manifestações apareceram, relacionando com a existência de responsável técnico, projeto aprovado dos imóveis e sinais de manutenção.

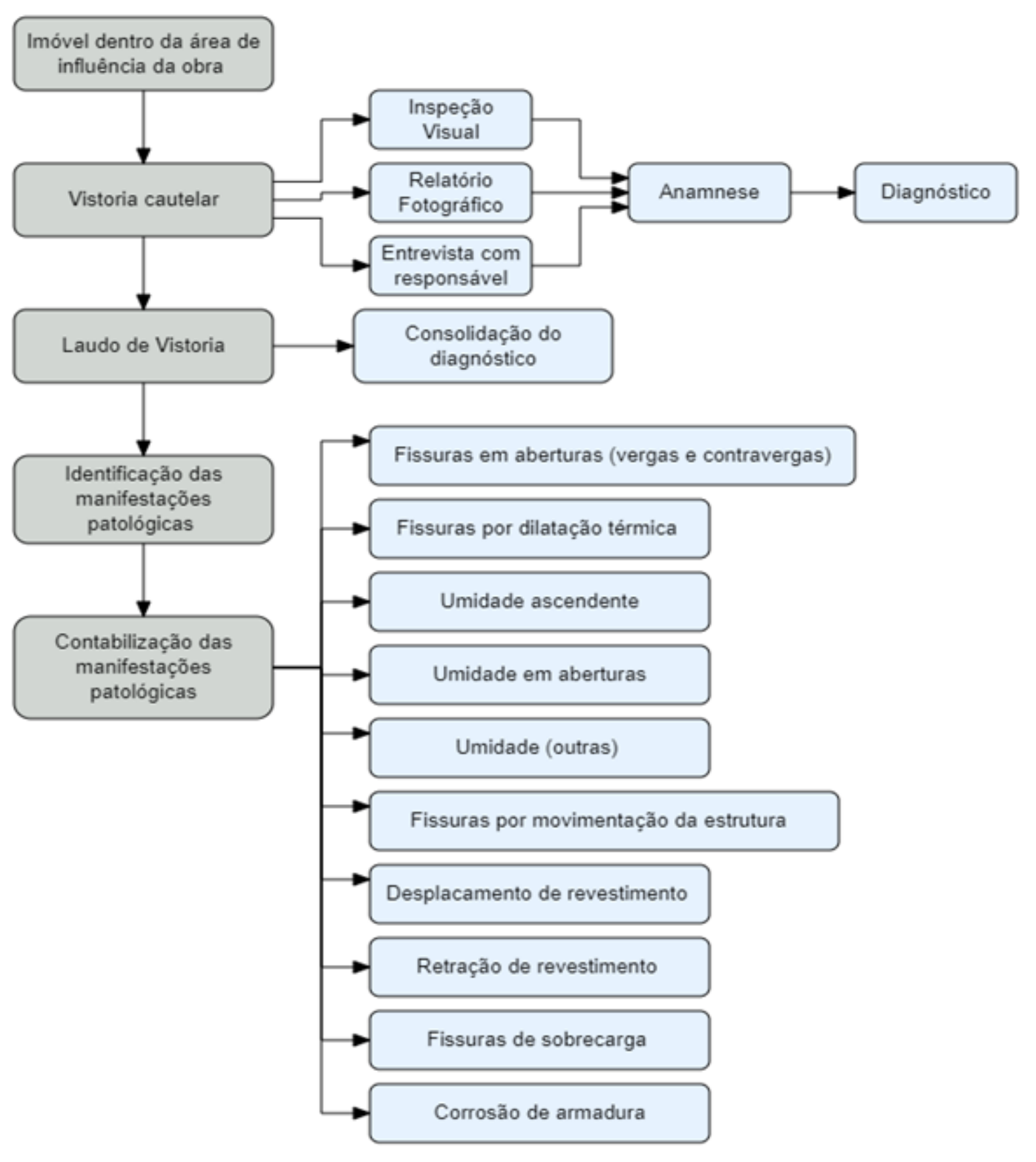

Figura 1 - Fluxograma do trabalho proposto.

Foram analisados os laudos de caráter detalhado, totalizando então 155 laudos, e em planilha digital, as manifestações patológicas analisadas foram: fissuras em aberturas (por ausência ou ineficiência de verga e contra verga), fissuras de amarração entre paredes de alvenaria, fissuras por dilatação térmica, umidade (ascendente, em aberturas e outras origens, como acidental e cobertura), fissuras por movimentação da estrutura, desplacamento do revestimento, retração de revestimento, fissuras de sobrecargas, fissuras estruturais (flexão, compressão, cisalhamento) e corrosão de armadura. Cada imóvel foi identificado com a presença ou não da sintomatologia, de forma dicotômica.

Considerando que o trabalho em campo contemplou duas cidades distintas, que os imóveis vistoriados tiveram padrões e tipologias divergentes em cada região, optou-se por realizar uma análise em separado, 
assim pode-se identificar as manifestações patológicas mais frequentes quando se tem maior número de imóveis residenciais ou comerciais.

Os imóveis vistoriados na cidade 01 estão localizados em sua grande maioria em regiões periféricas de expansão urbana, afastadas do centro da cidade. A cidade possui um PIB per capita (IBGE, 2020) de R\$ 32.610,37, população de 133.865 habitantes. Cidade com altitude de 956 metros em relação ao nível do mar.

Enquanto que os imóveis na Cidade 02 estão localizados em cidade mais desenvolvida, próximos ao centro da cidade, em um dos principais acessos rodoviários. A cidade possui PIB per capita (IBGE, 2020) de $\mathrm{R} \$ 42.203,23$, população de 355.336 habitantes. Cidade com altitude de 975 metros em relação ao nível do mar.

\section{Resultados}

O capítulo será subdividido em três seções: Cidade 01, Cidade 02 e discussão dos resultados. A primeira relata as manifestações patológicas identificadas na Cidade 01. A segunda aborda as manifestações patológicas identificadas na Cidade 02. A terceira seção discute os resultados obtidos na elaboração do trabalho.

\subsection{Cidade 01}

Nesta seção, serão abordadas as manifestações patológicas identificadas na Cidade 01. Caracterizada como uma cidade menos desenvolvida do que a Cidade 02, foram vistoriados 36 imóveis residenciais (63\%) e 21 comerciais (37\%) e se encontram afastados do centro da cidade.

A idade estimada média dos imóveis vistoriados é de 21.32 anos, podendo ser dividido em classes para melhor observar a frequência, conforme Figura 2.

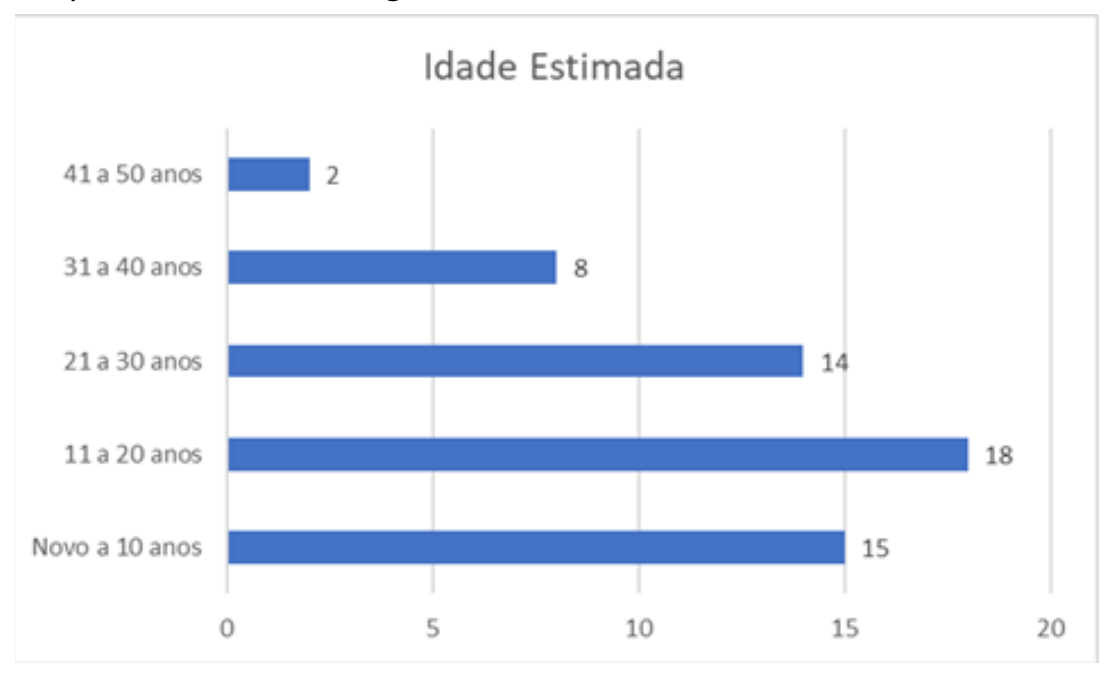

Figura 2 - Idade estimada dos imóveis da Cidade 1

Através das informações colhidas no momento da vistoria, foi possível estimar a quantidade de imóveis que possuem responsável técnico pela obra (projeto aprovado perante a municipalidade), totalizando 35 imóveis sem responsável técnico e 22 com responsável técnico.

No momento das vistorias e contato com os responsáveis pelos imóveis, foi possível analisar se o imóvel já havia passado por algum tipo de manutenção ou não. Assim, estimou-se que 31 dos 57 imóveis não haviam tido manutenção, enquanto que 26 já haviam recebido algum tipo de manutenção.

Assim, após realizadas todas vistorias e elaboração dos laudos técnicos, pode-se contabilizar a recorrência de cada manifestação patológica. Conforme apresentado na Figura 3, pode-se constatar que umidade ascendente foi a principal patologia diagnosticada, e fissuras decorrente da inexistência ou ineficiência de vergas ou contra vergas. 


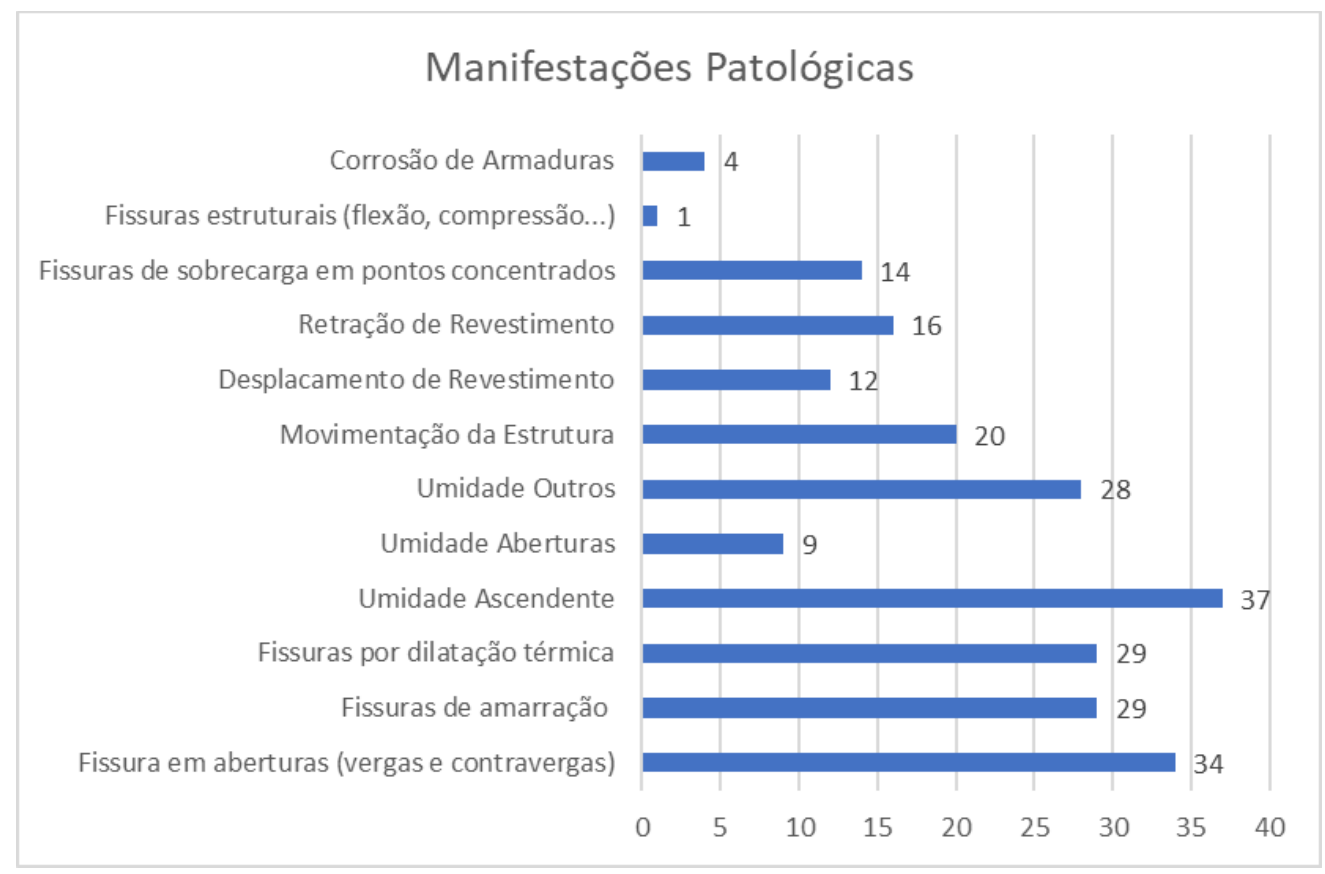

Figura 3 - Manifestações patológicas identificadas na Cidade 01

\subsection{Cidade 02}

Nesta seção, serão abordadas as manifestações patológicas identificadas na Cidade 02. Caracterizada como uma cidade mais desenvolvida do que a Cidade 01, foram vistoriados 19 imóveis residenciais (20\%) e 77 comerciais (80\%).

A idade estimada média dos imóveis vistoriados é de 30.41 anos, podendo ser dividido em classes para melhor observar a frequência, conforme apresentado na Figura 4.

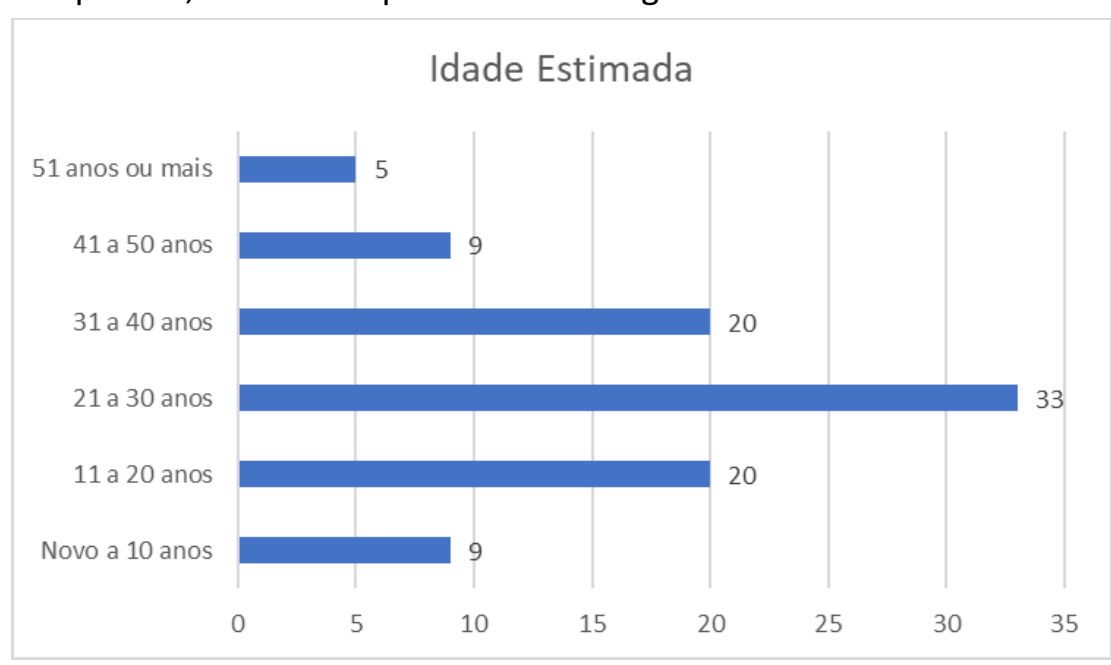

Figura 4 - Idade estimada dos imóveis da Cidade 2

Através das informações colhidas no momento da vistoria, foi possível estimar a quantidade de imóveis que possuem responsável técnico pela obra (projeto aprovado perante a municipalidade), totalizando 42 imóveis sem responsável técnico e 54 com responsável técnico.

No momento das vistorias e contato com os responsáveis pelos imóveis, foi possível analisar se o imóvel já havia passado por algum tipo de manutenção ou não. Assim, estimou-se que 81 dos 96 imóveis não haviam tido manutenção, enquanto que 15 já haviam recebido algum tipo de manutenção.

Assim, após realizadas todas vistorias e elaboração dos laudos técnicos, pode-se contabilizar a recorrência de cada manifestação patológica. Conforme apresentado na Figura 5, pode-se constatar que umidade 
ascendente foi a principal patologia diagnosticada, e fissuras decorrente da inexistência ou ineficiência de vergas ou contra vergas.

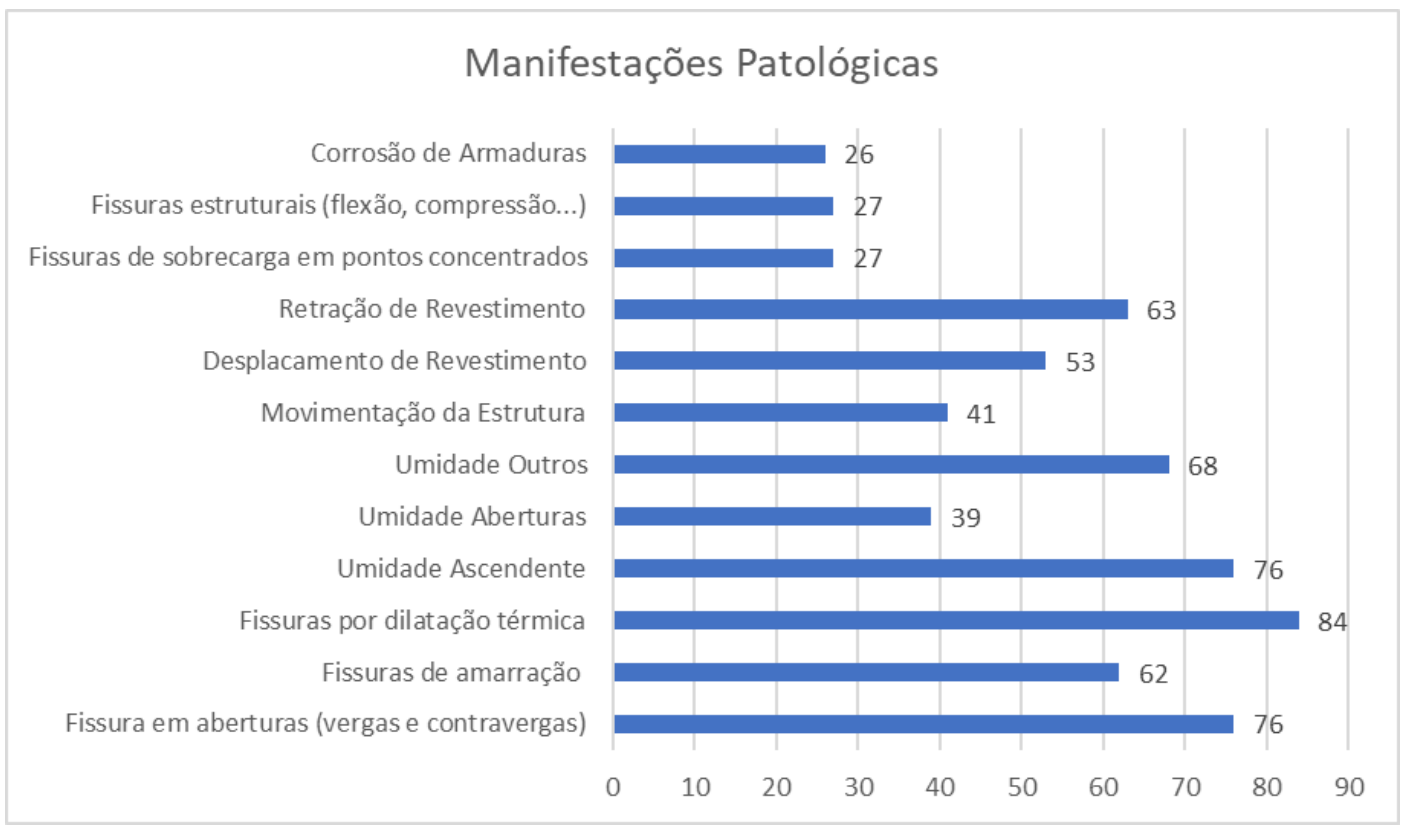

Figura 5 - Manifestações patológicas identificadas na Cidade 02

\subsection{Discussão}

Com base na análise dos resultados obtidos para Cidade $01,63 \%$ dos imóveis vistoriados são residenciais e $37 \%$ comerciais, com uma idade média de 21.31 anos, situados em região afastada do centro da cidade. Enquanto que a Cidade 02 teve $80 \%$ de imóveis comerciais e $20 \%$ residencial, com uma idade estimada média de 30.41 anos, situados em uma região mais central de uma cidade maior e mais desenvolvida.

Foi possível analisar que os imóveis da Cidade 01 tiveram menor percentual de edificações com projeto aprovado (aproximadamente 38\%) do que quando comparado com a Cidade 02 (aproximadamente 56\%). Quando analisado a manutenção dos imóveis, identificou-se que a Cidade 01 teve maior índice de reparos, com $45 \%$ dos imóveis, enquanto que a Cidade 02 com apenas $15 \%$ dos imóveis com sinais de manutenção.

Quando do estudo das manifestações patológicas, na Cidade 01 foi mais recorrente a umidade ascendente (em $65 \%$ dos casos), fissura em aberturas (60\% dos casos) e fissuras por dilatação térmica e de amarração ( $50 \%$ dos casos). Enquanto que na Cidade 02, as manifestações patológicas mais recorrentes foram: fissuras por dilatação térmica ( $87,5 \%$ dos casos), umidade ascendente e fissuras em aberturas ( $79 \%$ dos casos).

\section{Conclusões}

O presente estudo realizou o levantamento das manifestações patológicas identificadas nos imóveis vistoriados, de forma a possibilitar concluir que as etapas do ciclo de vida das edificações mais envolvidas no surgimento de manifestações patológicas são: projeto e execução. Corroborando com isso, tem-se o baixo número de imóveis com projeto aprovado junto a municipalidade em ambas as cidades.

Através do trabalho realizado, foi possível identificar a diferença de manutenção entre regiões comerciais e residenciais. A região residencial teve maior índice de manutenção, enquanto que o comercial teve menor índice. Atribui-se este resultado ao fato que os ocupantes dos imóveis comerciais, por estarem trabalhando e não residirem no local, não possuem os mesmos cuidados e atenção com a manutenção do imóvel.

Em relação ao objetivo principal proposto neste estudo, conclui-se que o mesmo foi atingido. Foi realizado o levantamento das manifestações patológicas constatadas nas benfeitorias vistoriadas. Além de ter cumprido com os objetivos secundários: correlacionar o contexto da localização com as manifestações patológicas identificadas, quantificar a diferença de frequência de manutenção entre regiões residenciais e comerciais e identificar a etapa do ciclo de vida das edificações que origina o maior número de manifestações patológicas. 


\section{Referências Bibliográficas}

ASSOCIAÇÃO BRASILEIRA DE NORMAS TÉCNICAS. NBR 13752: Perícias de engenharia na construção civil. 1 ed. Rio de Janeiro: Abnt, 1996. 8 p.

ASSOCIAÇÃO BRASILEIRA DE NORMAS TÉCNICAS. NBR 14653-1: Avaliação de Bens - Parte 1: Procedimentos Gerais. 4 ed. Rio de Janeiro: Abnt, 2019. 19 p.

ASSOCIAÇÃO BRASILEIRA DE NORMAS TÉCNICAS. NBR 16747: Inspeção Predial - Diretrizes, conceitos, terminologia e procedimento. 1 ed. Rio de Janeiro: Abnt, 2020. $14 \mathrm{p}$.

Cánovas, M. F. (1988). Patologia e Terapia do Concreto Armado. 1. ed. São Paulo: PINI.

Gomide, T. L. F., Neto, J. C. P. F., Gullo, M. A. (2009) Engenharia Diagnóstica em Edificações. 1a ed. São Paulo: PINI.

Helene, P. R., Do, L. (1988) Corrosão de armaduras para concreto armado. In: Tecnologia de Edificações1. São Paulo: PINI, p. 597-602.

BRASIL. IBGE. IBGE Cidades. 2020. Disponível em: https://cidades.ibge.gov.br/brasil/pesquisa/22/28120. Acesso em: 05 set. 2020.

Mehta, P. K., Monteiro, P. J. M. (2008) CONCRETO: Microestrutura, Propriedades e Materiais. 1a Edição ed. São Paulo: IBRACON.

Milititsky, J., Consoli, N. C., Schnaid, F. (2015) Patologia das Fundações. 2. ed. São Paulo: Oficina de Textos.

Perezes, A. R. (1988) Umidade nas edificações: recomendações para a prevenção da penetração de água pelas fachadas (1a. parte). In: Tecnologia de Edificações. 1a Ed ed. São Paulo: PINI, p. 708.

Richter, C. (2007) Qualidade da alvenaria estrutural em habitações de baixa renda: uma análise da confiabilidade e da conformidade. [s.I.] Universidade Federal do Rio Grande do Sul..

Thomaz, E. (2001) Tecnologia, Gerenciamento e Qualidade na Construção. 1a Edição ed. São Paulo: PINI.

Tuutti, K. (1982) Corrosion of steel in concrete. [s.I.] Lund University - Stockholm.

Verçoza, E. J. (1989) Patologia da Umidade. Simpósio sobre Patologia das Edificações: Prevenção e Recuperação. Anais...Porto Alegre: UFRGS. 